\title{
Outcome of Tendon Transfer Around Shoulder with Erb's Palsy Internal Rotation Deformity
}

\author{
FAROUK E. FAROUK, M.Sc.; MUHAMMAD A. ROMEIH, M.D.; ABD EL-HAFEZ A. MEGAHED, M.D. and \\ MOSTAFA A. AYOUB, M.D.
}

The Department of Orthopaedic Surgery and Traumatology, Faculty of Medicine, Tanta University, Tanta, Egypt

\begin{abstract}
Background: Obstetric Brachial Plexus Palsy (OBPP) is one of the most severe complications at birth with internal rotation deformity that have significant functional disability. There is a many different methods of tendon transfer that have been descried to improve the shoulder Range of Motion (ROM)
\end{abstract}

Aim of Study: Evaluate the outcome of teres major tendon transfer around the shoulder in children with Erb's palsy internal rotation deformity.

Methods: This study was Retrospective and prospective randomized clinical study carried out on totally (25) patients admitted to Orthopaedic Department of Tanta University Hospital. Ten children represented the Retrospective portion of the study, and fifteen represented the prospective portion. All cases were operated by Modified Sever-L'Episcopo technique. The external rotation, according to Mallet score, was recorded pre-and post-operatively.

Results: The mean follow-up period was twelve months (range 6-18). The Mallet score for the shoulder external rotation, at the end of follow-up periods, was graded as Grade II in two patients (8\%), Grade III in nine patients (36\%), and Grade IV in fourteen patients $(56 \%)$. There was a highly significant improvement $(p=0.00001)$ of the external rotation range as the mean pre-operative score was $2.04 \pm 0.02$, and the mean post-operative score was $3.48 \pm 0.65$.

Conclusion: The Modified Sever L'Episcopo procedure that compromises of anterior release, then teres major tendon transfer to the tendon of infraspinatus shows a high incidence of good outcome with a promising subjective and objective improvement in almost cases.

Key Words: Tendon transfer - OBBP - Erb's palsy - Modified sever L'Episcopo procedure.

\section{Introduction}

Arm paralysis from birth injury was first described by Smellie [1] in 1764, but classic description of

Correspondence to: Dr. Farouk E. Farouk, The Department of Orthopaedic Surgery and Traumatology, Faculty of Medicine, Tanta University, Tanta, Egypt shoulder paralysis, internal rotation contracture and waiter's tip deformity was given by Erb in 1874 as cited by Gilbert A et al., [2] traction injury to the brachial plexus occurs during difficult delivery [3].

Obstetric Brachial Plexus Palsy (OBPP) affects 0.1 to $0.4 \%$ of births [4]. Despite an increase in caesarean section rates and a decline in the number of vaginal breech deliveries in recent years, one possible reason being the concurrent increase in birth weight [5]

Obstetric palsy of the upper limb is caused by traction injury to the brachial plexus which leads to stretching of the cervical nerve roots (C5, C6, C7) of brachial plexus. Permanent damage to the upper roots is uncommon, but causes a deformity and a severe functional deficit. Clinically, there is a loss of abduction and external rotation of the shoulder, flexion at the elbow and supination of the forearm [6]

The cause of muscle imbalance around shoulder is that weak external rotators and abductors (supraspinatus, infraspinatus, posterior and middle fibers of deltoid), while adductors and internal rotators are normal in strength (pectoralis major, coracobrachialis, pectoralis minor, subscapularis, teres major and latissimus dorsi). This asynergy leads to formation of persistent internal rotation and adduction contractures of shoulder by six months of age [3]

Different soft-tissue releases and transfers have been described, such as the release of the subscapularis and the capsule by Fairbank [7], release of the subscapularis and the pectoralis major by Sever $[\mathbf{8 , 9}]$ 
L'Episcopo [10] observed the recurrence of internal rotation deformity following Sever's procedure. Therefore, he described a technique for detaching the latissimus dorsi and teres major muscles from their insertions and transferring them posteriorly and laterally so that they become external rotators $[3,10,11]$.

Also, Green and Tachdjian [12] described lengthening the pectoralis major and subscapularis muscles in addition to transferring latissimus dorsi and teres major muscles to resolve the recurrence problem after the surgical release only [13] .

The aim of this study was to evaluate the functional outcome of anterior release and posterior teres major transfer (modified Sever-l'Episcopo technique) in children with a handicapping internal rotation deformity due to Erb's palsy.

\section{Patients and Methods}

This study was retrospective and prospective randomized clinical study carried out on 25 children admitted to Orthopaedic Department of Tanta University Hospital. Ten children represented the retrospective portion of the study and fifteen children represented the prospective portion. All children were operated by the modified Severl'Episcopo technique in the period from December 2010 to November 2015.

The inclusion criteria were children with stable shoulder, aged 2 to 7 years old, diagnosed with upper/upper-middle type of OBPP, with internal rotation deformity of the shoulder and shoulder abduction about $90^{\circ}$ or more. While, the main exclusion criteria were: Children with flail limb; aged less than 2 years or more than 7 years; children with total type of OBPP; children with a previous related surgical intervention; and children presented with dislocated head of the humerus or shoulder abduction less than $90^{\circ}$.

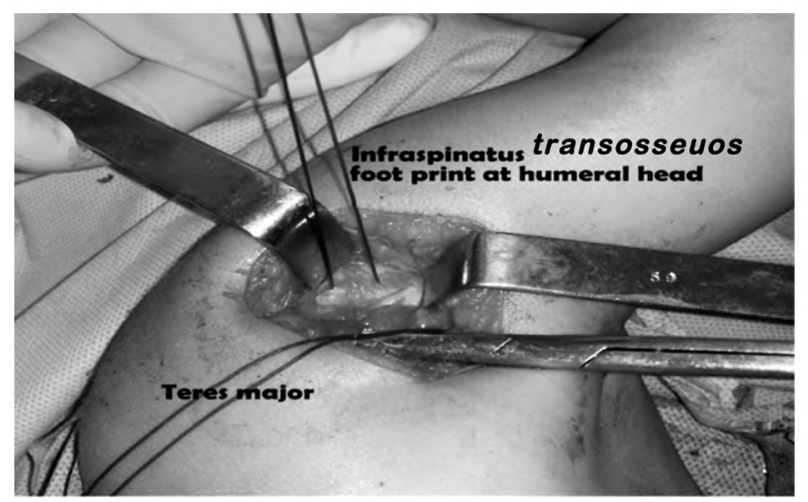

Fig. (1): Tendon transfer.
All children were subjected to complete history taking, full clinical examination with preoperative and post-operative active external rotation assessment using the Mallet score [14]. Plain radiographs of both shoulders, Electromyography (EMG) and nerve conduction studies were created for all included children.

Surgical technique: The Modified Severl'Episcopo technique was performed uniformly to all included children in this study, firstly the child was positioned supine for anterior approach which made over the deltopectoral groove then anterior release (sever) was done according to the degree of the contracture by releasing the coracoacromial ligament, subscapularis, coracobrachialis and pectoralis major muscles. Then the child turned over to the lateral position for the posterolateral incision which made over lateral border of the scapula, then the teres major is dissected and detached from its insertion at humerus and reinserted at foot print of infraspinatus tendon with transosseuos sutures at the greater tuberosity using non-absorbable suture and another sutures to the infraspinatus tendon Fig. (1). This direct Tendon to Tendon anastomosis preserving the tension of transferred tendon within an angle about $20^{\circ}-50^{\circ}$ degree of external rotation to overcome any expected relaxation later on Fig. (2). Post-operatively, shoulder spica was applied in abduction $90^{\circ}$ and external rotation $90^{\circ}$ for 6 weeks. After the removal of spica, a strict physiotherapy and rehabilitation protocol was applied for all children.

The results were analysed statisically using SPSS Version 11.0.1 for Windows (SPSS Inc., Chicago, IL). Chi-square test was applied for tabulating data according to the table cells. Paired $t$-test was used for means of comparison. $p$-value $\leq 0.05$ was considered statistically significant.

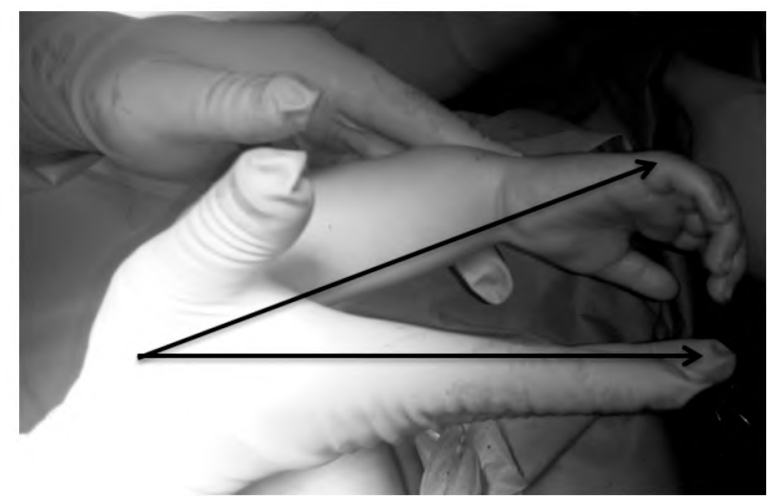

Fig. (2): Intraoperative demonstration of the tension of the transferred tendon. 


\section{Results}

All children were followed-up; no one was missed. The shortest follow-up period was six months, while the longest was eighteen months with a mean follow-up period of twelve months.

According to Mallet score [14] external rotation evaluation, the mean pre-operative score was 2.04 , and the mean post-operative score was 3.48 (mean increase in external rotation grade was about 1.44). There was a highly significant improvement $(p=$ 0.00001 ) of the active external rotation range with definite subjective and objective improvement in all children (Table 1) Figs. $(3,4)$ two cases with pre and final post-operative photos).

The complications were encountered in seven patients $(28 \%)$ including: Wound infection in two patients $(8 \%)$ which settled with antibiotics; and hypertrophic scar in five patients $(20 \%)$.

The younger age children had better functional end result $(p$-value $=0.00626)$ than the older aged children Fig. (5).
Furthermore, the upper OBPP has better improvement in the final shoulder external rotation ( $p$-value $=0.001648)$ than upper/middle lesion Fig. (6).

The other factors like sex, side of the lesion and the complications had no significant effect in the functional end results.

Table (1): Pre-and post-operative external rotation grades according to Mallet's score.

\begin{tabular}{llc}
\hline $\begin{array}{l}\text { External rotation } \\
\text { score }\end{array}$ & Grades & Mean \pm SD \\
\hline Pre-operative & Grade II in (24) children & $2.04 \pm 0.2$ \\
& Grade III in (1) child &
\end{tabular}

Post-operative Grade II in (2) children

$3.48 \pm 0.65$

Grade III in (9) children

Grade IV in (14) children

Paired-t-test:

$t \quad-11.066$

$p$-value

$<0.00001^{*}$

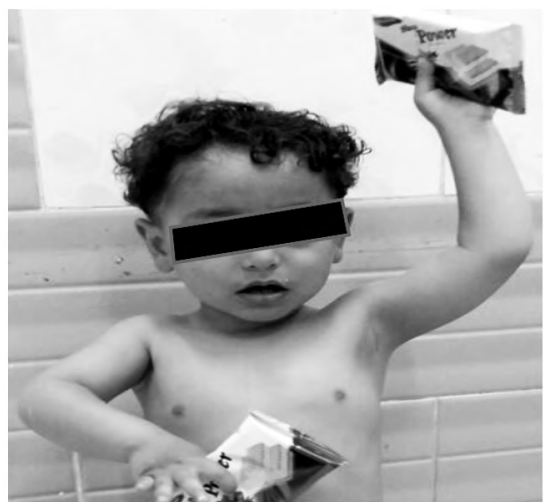

(A)

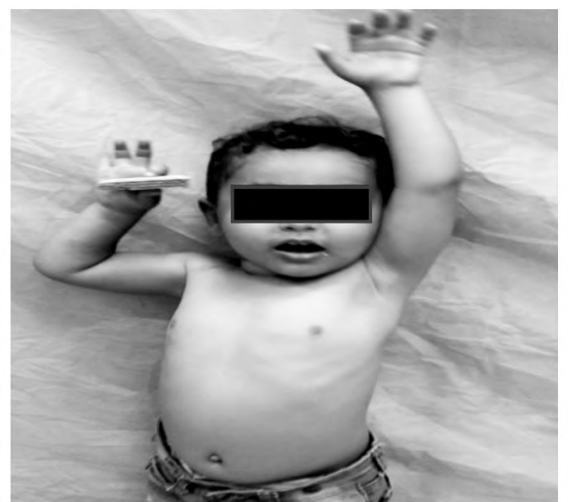

(B)

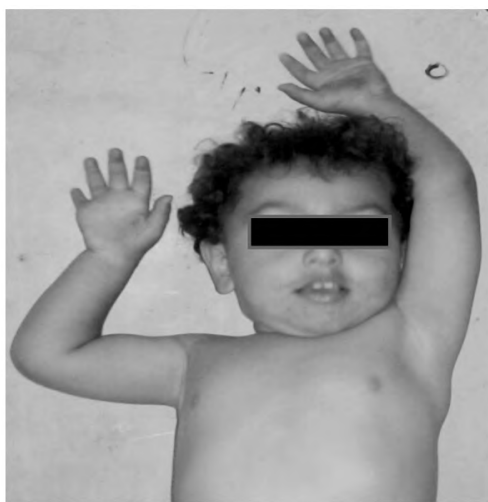

(C)

Fig. (3): Boy child aged two and half years old (age at the time of operation) with upper type-OBPP in the right upper limb (A) Pre-operative evaluation of the shoulder External Rotation Mallet Score Grade II about $0^{\circ}$ (B) Post-operative follow-up assessment after 4 months External Rotation Mallet Score Grade III about $>20^{\circ}$ (C) Final follow-up assessment after 12 months External Rotation Mallet Score Grade IV about $<20^{\circ}$.

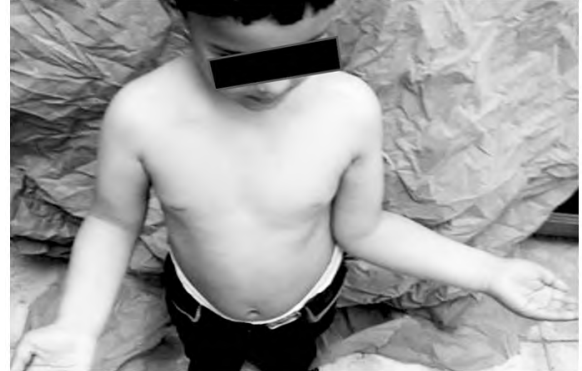

(A)

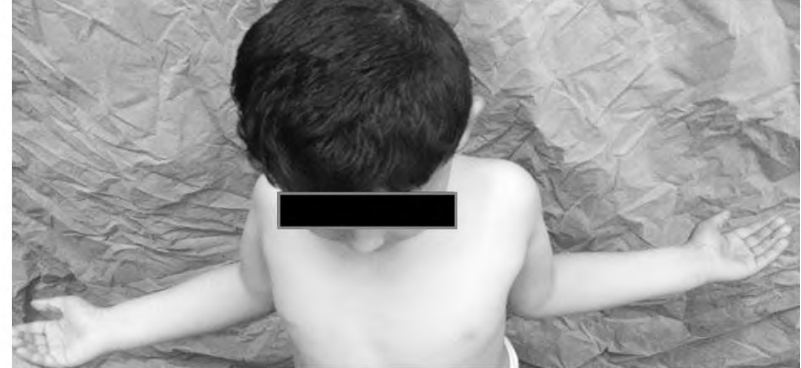

(B)

Fig. (4): Boy child (retrospective portion of the study), his age at the first follow-up in this study, was four and half years old, the age at operation was three and half years old, upper type-OBPP in his right upper limb (A) Pre-operative evaluation of the shoulder External Rotation Mallet Score Grade II about $0^{\circ}(\mathrm{B})$ Final follow-up assessment after 18 months External Rotation Mallet Score Grade IV about $<20^{\circ}$. 


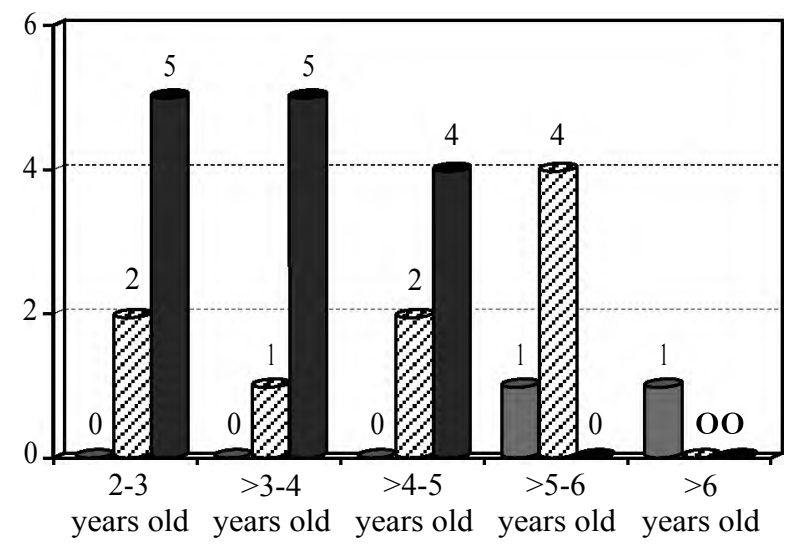

$$
\text { Grade II Grade III Grade IV }
$$

Fig. (5): Chart showing relation between the age at the time of operation and the functional end results.

\section{Discussion}

The most common residual deformity after birth palsy is restricted external rotation of the shoulder. This is frequently associated with an internal rotation contracture and a cascade of skeletal deformities such as coracoid elongation, a hooked acromion, flattening of the humeral head.

The Modified Sever L'Episcopo procedure was performed uniformly on all children in this study. Our surgical procedure comprises of anterior release, then teres major tendon transfer to the infraspinatus tendon. The final mean increase in external rotation score, in this series, was about 1.44 with significant improvement of the final active external rotation range.

In Ahmed and Hashmi procedure; [3] the anterior release was an with mean increase in external rotation score was about 1.5 , Waters et al., [16] had anterior release of pectoralis major with a mean increase in external rotation score about 2, Kirkos et al., [17] also did anterior shoulder release, finally their average increase in external rotation was 12 degrees, furthermore, Green and Tachdjian [12] did anterior release of the subscapularis muscle, with an average increase in external rotation for about $46^{\circ}$, but only lengthening of pectoralis major and subscapularis muscle without anterior release was done by Chomiak et al., [13] with mean increase in External rotation score was about 1.44. On the other hand, no anterior release was done by Covey et al., [11] and they had an average increase in external rotation about 29 degrees.

By comparison of those results, it was found that there is no much significant improvement of

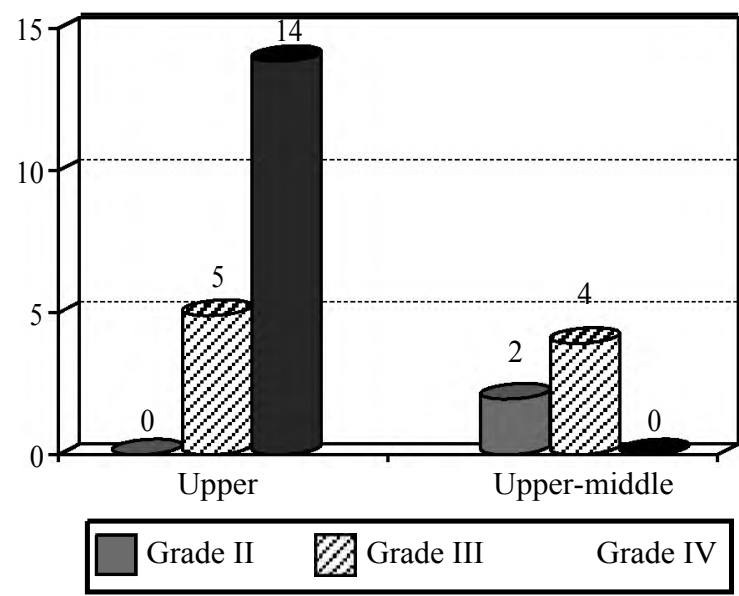

Fig. (6): Chart showing relation between the type of OBPP and the functional end results.

the end results in the procedure accompanied by anterior release comparable to the other procedure with anterior lengthening or even not doing release at all. However, anterior release ensured adequate passive external rotation in our study.

Regarding Tendon transfer procedure; there are different methods with different effect to the results. The procedure of Tendon transfer of the latissimus dorsi and teres major to the lateral side of the humerus was formally performed by Chomiak et al., [13], Odeh and Odeh procedure, [18] and Green and Tachdjian [12] procedure. Another procedure of Tendon transfer of the latissimus dorsi and teres major to the rotator cuff was performed in Ahmed and Hashmi [3] study, Waters et al., procedure, [16] and Hoffer and Phipps study [19]. On the other hand. Al-Qattan technique [20] consists of by Latissimus Dorsi transfer either to the rotator cuff (older children) or directly to the humeral head (younger children) the results gave variable end results with modified mallet score from class 3 to class 4. Also, Covey et al., [11] procedure depends on modification of the L'Episcopo procedure by replacing the osteoperiosteal flap with direct tendon to tendon anastomosis without anterior releases. Recently, Kirkos et al., [17] had tendon transfer of latissimus dorsi and teres major tendon posteriorly and laterally and sutured to the humeral stump of the previously divided tendon of pectoralis major. The results showed an average increase in external rotation by 12 degrees.

Finally, we found the result of our tendon transfer procedure is standing midway in relation to the results of these different procedure of tendon transfer. 
In the present study, the shortest follow-up period was six months, while the longest was eighteen (18) months with functional end results mean increase in Mallet score of external rotation about 1.44. However, longer regular follow-up period was nearly about 24 months with Chomiak et al., [13] and Ahmed and Hashmi [3] studies with nearly similar results with the functional end results (increase in the mean Mallet score of external rotation about 1.44). Waters et al., [16] the followup period was about 28.8 months with a mean increase in external rotation Mallet grade was about 2, Odeh and Odeh [18] the follow-up period was about 39 months with increase in the mean external rotation Mallet grade about 2.7, i.e. both are better than the functional end results of this study. Hence, it seems that longer follow-up period leading to better end results with more increase in the mean external rotation of the Mallet score, the short follow-up period to the cases is a limitation to this study in comparison to the follow-up periods in the other studies.

In this study, complications found in seven cases $(28 \%)$. They included: Wound infection in two cases which settled with antibiotics and Hypertrophic scar in five cases. No post-operative axillary nerve palsies were encountered. In Ahmed and Hashmi [3] study, one hypertrophic scar was seen. One patient had superficial wound infection, which settled with antibiotics. No post-operative axillary nerve palsies were encountered. Self-resolving radial nerve neuropraxia occurred in one case. After the removal of spica. In Odeh and Odeh [18] study, one patient with superficial wound infection, which settled with antibiotics. Two cases had axillary nerve palsy presenting as weakness in abduction of the shoulder, which recovered in two to three months. Kirkos et al., [17] had only one patient with hypo aesthesia in the area of the superficial radial nerve. Covey et al., [11] had two cases with complications one required subscapularis tenolysis two years later, the other patient had partial rupture or attenuation of the tendon anastomosis, Al-Qattan [20] had no immediate postoperative complications, such as infection, hematoma, or iatrogenic nerve injury were seen. However, three children developed a seroma at the donor site in the back and these were treated conservatively. At follow-up, late-onset complications were seen in two cases who had both had uneventful initial post-operative courses, and at 6 months post-operatively had achieved modified Mallet scores of 4 . However, both had then gradually lost active external rotation and at final follow-up their Mallet scores had dropped back to 2 .
In this study, the Mallet score was used as an evaluation method for the ROM pre- $\&$ postoperative follow-ups (functional end results). The Mallet grading system is a commonly used functional scoring system to assess shoulder abduction/ external rotation deficits in children with obstetric brachial plexus palsy. One feature of the Mallet score is that each grade is translated into certain degrees of deficiencies in both shoulder abduction and external rotation. Clinically, the surgeon tailors the indications of surgery depending on the degree of the deficit of every joint motion. However, the Mallet score is frequently used in research papers to assess the combined deficits at both shoulder abduction and external rotation [21]. On the other side, some authors as Covey et al., [11], Green and Tachdjian [12], Hoffer and Phipps [19], Kirkos et al., [17] depended on measuring the angles of the preoperative and postoperative external rotation. Which supposed to be difficult with the child cooperation and assessment.

The age of the children at time of operation had statistically significant impact on the functional end results. In this study, average age at the time of operation about 3.75 years (45 months) ranged from 2 years old to 7 years old with mean increase in external rotation grade about 1.44 . With nearly similar average age at the time of operation in Waters et al., [16] study about 48 months, but the results show mean increase in external rotation grade about 2 . Also, nearly similar age in Al-Qattan [20] study average age about 42 months which gives variable end results with modified mallet score from class 3 to class 4 at the final followup. Another, nearly similar age with Green and Tachdjian [12] procedure who modified the SeverL'Episcopo procedure, performed for below the age of six years. With an average increase in external rotation for about $46^{\circ}$. With younger average age at the time of operation about 28.6 months in Hoffer and Phipps [19] procedure, finally, they reported an average increase in external rotation about $65^{\circ}$. Also, older average age at the time of operation was about 75 months in the Ahmed and Hashmi [3] procedure, the mean increase in external rotation Mallet grade about 1.5 [3]. Furthermore, older average age at the time of operation was about 100.8 months in the Odeh and Odeh [18] study the mean increase in External rotation Mallet grade about 2.7. Finally, with older average age at the time of operation about 162 months in Chomiak et al., [13] study. The mean increase in external rotation Mallet grade about 1.44. Hence, most authors recommend repairing muscle imbalance early, in the second year of life, to prevent glenoid 
dysplastic changes [13] in this study better functional end results seem to be with younger age.

In the Table (2): Summarizes the demographic and clinical data of this study in comparison to other studies.

This study had many shortcomings including: The short follow-up periods; little number of the studied cases; absence of the control group; and the retrospective portion of the study.

\section{Conclusion:}

Anterior release and teres major tendon transfer in children with incomplete OBPP have a promising functional improvement especially among the younger age children and those with upper lesion type.

Table (2): Summary of the clinical data of this study in comparison to other studies.

\begin{tabular}{|c|c|c|c|c|c|}
\hline & $\begin{array}{l}\text { No. of } \\
\text { cases }\end{array}$ & $\begin{array}{c}\text { Average age } \\
\text { (mo) at } \\
\text { operation }\end{array}$ & $\begin{array}{l}\text { Average increase in } \\
\text { external rotation }\end{array}$ & $\begin{array}{l}\text { Follow-up } \\
\text { Period } \\
\text { months }\end{array}$ & Ant. release \\
\hline This study & 25 & 45 & $\begin{array}{l}\text { Mallet class } 2.24 \text { to } 3.48 \\
\text { Mean increase in ER grade about } 1.44\end{array}$ & 18 & $\begin{array}{l}\text { Yes Subscapularis muscle }+ \\
\text { coracohumeral ligament. }\end{array}$ \\
\hline $\begin{array}{l}\text { Chomiak et al., } \\
\text { [13] }\end{array}$ & 15 & 162 & $\begin{array}{l}\text { Mallet class } 2 \text { to } 3.44 \\
\text { Mean increase in ER grade about } 1.44\end{array}$ & 24 & $\begin{array}{l}\text { No. only PM \& subscapularis } \\
\text { muscle lengthening }\end{array}$ \\
\hline $\begin{array}{l}\text { Ahmed and } \\
\text { Hashmi [3] }\end{array}$ & 10 & 75 & $\begin{array}{l}\text { Mallet class } 2.8 \text { to } 4.3 \\
\text { Mean increase in ER grade about } 1.5\end{array}$ & 25 & Yes \\
\hline $\begin{array}{l}\text { Waters et al., } \\
{[16]}\end{array}$ & 9 & 48 & $\begin{array}{l}\text { Mallet class } 2 \text { to } 4 \\
\text { Mean increase in ER grade about } 2\end{array}$ & 28.8 & $\begin{array}{l}\text { Yes anterior release of } \\
\text { pectoralis major }\end{array}$ \\
\hline $\begin{array}{l}\text { Odeh and Odeh } \\
\text { [18] }\end{array}$ & 19 & 100.8 & $\begin{array}{l}\text { Mallet class } 1.4 \text { to } 4.1 \\
\text { Mean increase in ER grade about } 2.7\end{array}$ & 39 & $\begin{array}{l}\text { No. only PM \& subscapularis } \\
\text { muscles lengthening }\end{array}$ \\
\hline Al-Qattan [20] & 12 & 42 & Modified Mallet class 3 to 4 & 48 & No. \\
\hline $\begin{array}{l}\text { Covey et al., } \\
\text { [11] }\end{array}$ & 19 & 71 & 29 & 50.4 & No. \\
\hline $\begin{array}{l}\text { Green and } \\
\text { Tachdjian [12] }\end{array}$ & 22 & Below 72 & 46 & 72 & Yes. dividing the subscapularis. \\
\hline $\begin{array}{l}\text { Hoffer and } \\
\text { Phipps [19] }\end{array}$ & 8 & 28.6 & 65 & 37 & $\begin{array}{l}\text { No. recession of subscapularis } \\
\text { muscle }\end{array}$ \\
\hline $\begin{array}{l}\text { Kirkos et al., } \\
{[17]}\end{array}$ & 10 & 72 & 12 & 360 & Yes \\
\hline
\end{tabular}

\section{Conflicts of interest:}

There are no conflicts of interest.

\section{References}

1- SMELLIE W.: Collection of preternatural cases and observations in midwifery. Completing the Design of illustrating His first volume on that subject. Vol. III. London: Wilson and Durham; P 504, 1764.

2- GILBERT A., BROCKMAN R. and CARILOZ H.: Surgical treatment of brachial plexus birth palsy. Clin. Orthopaed.; 264: P 39-47, 1991.

3- AHMED S.K. and HASHMI P.M.: Restoration of glenohumeral motion in Erb's palsy by tendon transfers. Journal of Ayub Medical College, Abbottabad: J.A.M.C.; 18 (2): P. 44-9, 2006

4- COHEN G., RAMPAL V., AUBART-COHEN F., et al. Brachial plexus birth palsy shoulder deformity treatment using subscapularis release combined to tendons transfer. Orthopaedics and Traumatology: Surgery and Research; 96 (4): p. 334-9, 2010
5- MOLLVERG M.: Obstetric Brachial Plexus Palsy; Göteborg, Sweden; P. 1-12. (thesis), 2007.

6- BOOME R.S. and KAYE J.C.: Obstetric traction injuries of the brachial plexus. Natural history, indications for surgical repair and results. J. Bone Joint Surg.; 70-B: p. $571-76,1988$

7- FAIRBANK H.A.T.: Birth palsy: Subluxation of the shoulder joint in infants and young children. Lancet; 1913 (1): p. 1217-23.

8- SEVER J.W.: Obstetrical paralysis. Surg. Gynecol. Obstet., 1927 (44): 547-9.

9- ATTIA M.E. and ABDELHADI E.E.: Modified Hoffer technique for treatment of internal rotation deformity in obstetric brachial plexus palsy.; (March 2006): 45-50. doi: 10.7123/01.EOJ.0000426255.51180.a8, 2013.

10- L'EPISCOPO J.B.: Tendon transplantation in obstetric paralysis. Am. J. Surg.; 25: p. 122-5, 1934.

11- COVEY D.C., RIORDAN D.C., MILSTEAD M.E., et al.: Modification of the L'Episcopo procedure for brachial 
plexus birth palsies. The Journal of Bone and Joint Surgery \{Br\}; 74: p. 897-901, 1992.

12- GREEN W.T. and TACHDJIAN M.O.: Correction of residual deformities of the shoulder in obstetrical palsy. J. Bone Joint Surg. (Am.); 45: p. 1544-5, 1963.

13- CHOMIAK J., DUNGL P., O ST'ÁDAL M., et al.: Muscle transfers in children and adults improve external rotation in cases of obstetrical brachial plexus paralysis: A comparative study. International Orthopaedics; 38 (4): p. 80310, 2014.

14- MALLET J.: Paralysie obstétricale du plexus brachial. Traitement des séquelles. Primauté du traitement de l'épaule-méthode d'expression des résultats, Rev. Chir. Orthop., (58), suppl 1: p. 166-8, 1972.

15- Recovery after brachial plexus injury-Mallet classification Orthopaedics One Articles. In: Orthopaedics One-The Orthopaedic Knowledge Network. Created May 22, 2012 02: 22. Last modified May 22, 2012 09: 40 ver.235. Retrieved 2016-10-25, from http://www.orthopaedicsone. com $/ \mathrm{x} / 9 \mathrm{oAXBO}$.

16- WATERS P.M., SMITH G.R. and JARAMILLO D. Glenohumeral deformity secondary to brachial plexus birth palsy. J. Bone Joint. Surg. Am.; (80): p. 668-77, 1998.
17- KIRKOS J.M., KYRKOS M.J., KAPETANOS G.A., et al.: Brachial plexus palsy secondary to birth injuries: Long-term results of anterior release and tendon transfers around the shoulder. Journal of Bone and Joint Surgery; 87-B (2): p. 231-5, 2005.

18- ODEH R. and ODEH M.: A modified Sever-L'Episcopo procedure for restoration of shoulder joint function in Erb's palsy. International orthopaedics; 39 (2): P. 309-17, 2015.

19- HOFFER M.M. and PHIPPS G.J.: Closed reduction and tendon transfer for the treatment of dislocation of the glenohumeral joint secondary to brachial plexus birth palsy. J. Bone Joint Surg. Am.; (80): p. 997-1001, 1998.

20- AL-QATTAN M.M.: Latissimus dorsi transfer for external rotation weakness of the shoulder in obstetric brachial plexus palsy. Journal of Hand Surgery; 28 B (5): p. $487-$ 90, 2003.

21- AL-QATTAN M.M. and EL-SAYED A.A.F.: Obstetric Brachial Plexus Palsy: The Mallet Grading System for Shoulder Function-Revisited. Hindawi Publishing Corporation Bio. Med. Research International; 2014 (Table 1): p. 1-3, 2014.

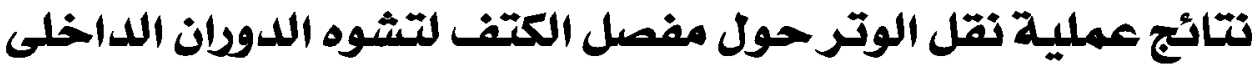

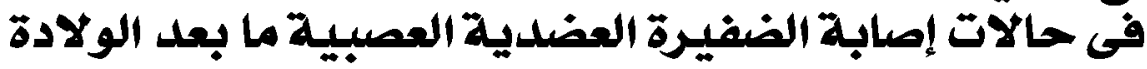

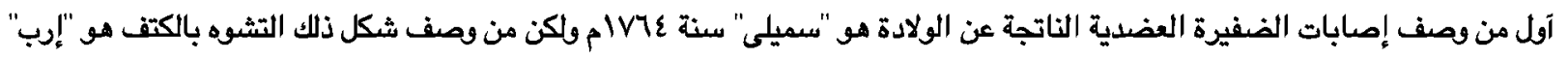

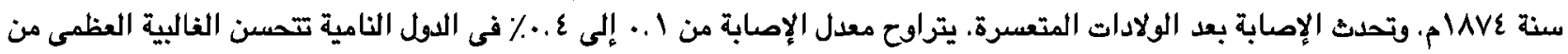

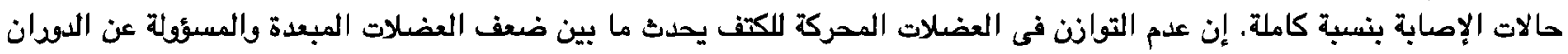

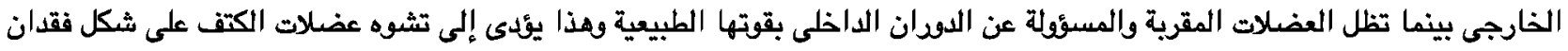

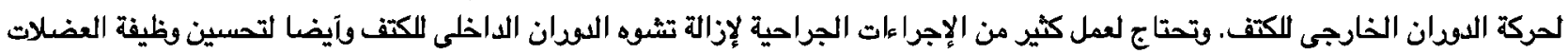

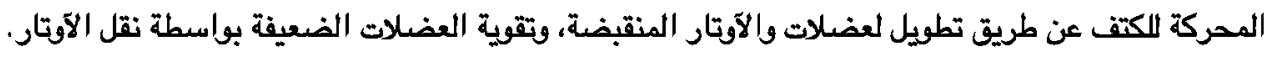

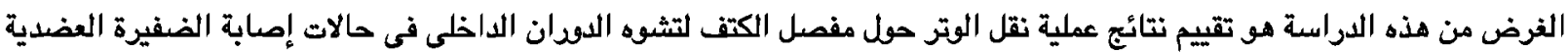

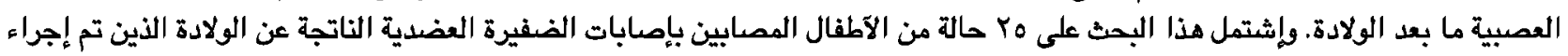

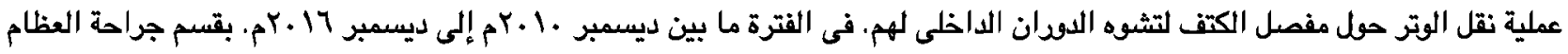

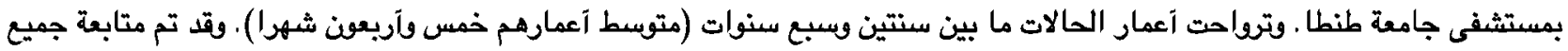

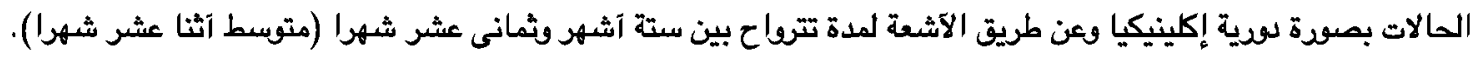

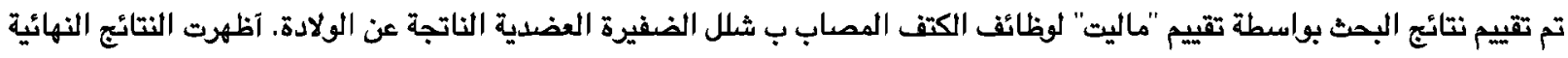

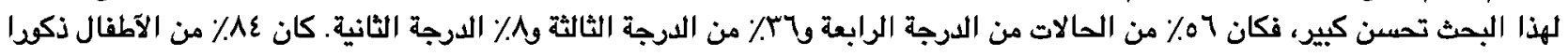

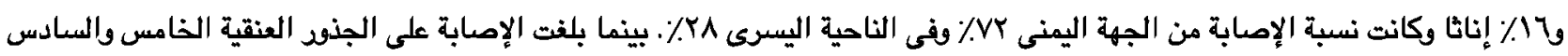

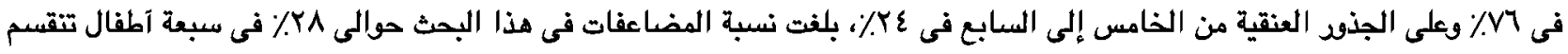

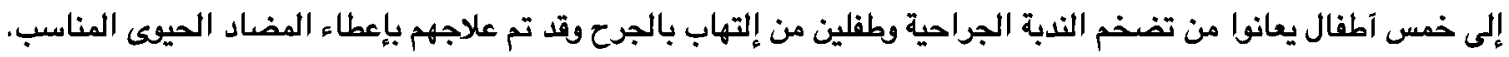

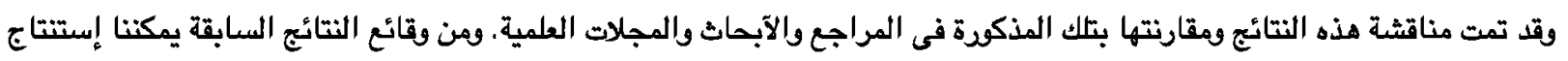

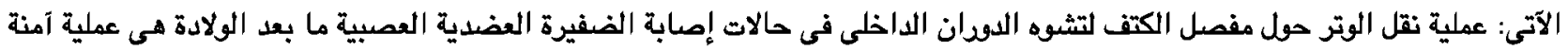
وتحقق تحسن كبير خصوصا في السن الصنير الصنير. 